\title{
Individuality, Collectivity and the Intersubjective Constitution of Intentionality
}

\author{
Patrizio Lo Presti \\ Depertment of philosophy, Lund University, Sweden \\ Department of logic, history and philosophy of science, UNED, Madrid \\ Patrizio.Lo_Presti@fil.lu.se
}

Received 26 August 2019; accepted 6 April 2020; published 11 July 2020

\begin{abstract}
This paper argues that first-person singular I- and first-person plural we-intentionality are constituted in normative second-person relations. Their relata are individuals who mutually recognize each other as loci of responsibility. Such relations constitute an I-You, which is argued to be sufficient for both singular I- and plural we-intentionality. Whenever there is I-intentionality there is we-intentionality, because whenever the relevant second-person relations obtain, conditions sufficient for both are satisfied. Consequently, the possibility of autonomous individual I-intentionality as well as plurally shared we-intentionality depends on at least two individuals involved in normative mutual recognition. Neither individual is an intentional ' $I$ ' independently of entering the I-You, and when they do so they are an intentional 'we.'
\end{abstract}

Keywords: intentionality; individuality; intersubjectivity; normativity; collectivity; autonomy; authority; inferentialism

\section{Introduction}

It is common to think of intentionality, in its most basic form, as a capacity of mind to be of or about something. Assuming there are no collective minds, intentionality is an individual capacity. This paper is not concerned with intentionality in that basic sense.

The form of intentionality concerned here is the capacity to think of or about things that they are thus-and-so. This is intentionality associated with the "I' in "I think..." - the emptiest of all forms to enjoin an "... of X," known to readers of Kant. This form of intentionality will here be considered in relation to the collective intentionality literature, which in its modern form celebrates thirty years. 
The early work on joint-, shared-, collective- and we-intentionality of Tuomela and Miller (1988), Gilbert (1989) and Searle (1990), among others, raised a worry about Hegelian spirits. The fundamentality of the intentional 'I' might be in jeopardy, if there is irreducible we-intentionality. But, reassuringly, Searle said that collective intentionality is a primitive form of intentionality caused and realized in individual brains - not some "Hegelian world spirit" (1995, p. 25) or other "abominable ... dreadful metaphysical excrescence" (1998, p. 150). Gilbert said that joint agency requires plural subjects. But plural subjectivity is a matter of a Rousseauesqe 'pooling of wills' of individual subjects. Others took the opportunity to argue that collectivity might be irreducible to individuality (e.g., Tollefsen, 2002; 2006). We are still struggling to make sense of it all (see, e.g., Crone and Huemer, 2018).

I will argue that I- does not presuppose we-intentionality, nor vice versa. The "I think..." makes as little sense as the plural "we think..." if taken in abstraction from an I-You context (Brandom, 1999; 2004). To speak with Schmid, the 'I' is just as spooky as the 'We' (2018, p. 242), though his reasons for saying so are different from those I advance. ${ }^{1}$

The points advanced here are, first, that all intentionality requires mutual recognition among individuals as intentional subjects. And, second, for intentionality to have determinate content requires that individuals articulate reasons for and against attributing, undertaking and acknowledging specific contents (Brandom, 2009). Thus, intentionality in the sense here considered is socially instituted (Haugeland, 1982; Baker, 2015).

The structure of the paper is as follows. First, I distinguish two senses of individual intentionality: a sense of sentient and a sense of sapient individual intentionality (section 2). I then take issue with sapient intentionality, arguing that it requires intersubjectivity (section 3). Sections 2 and 3 are by and large retrospective, in that they clarify, for those unfamiliar with it, what others have already had to say about different senses of individual intentionality and intersubjectivity. The last two sections are prospective, in that they elaborate, in ways only few, even of those familiar with the points rehearsed in the first two sections have, a new perspective on the issue of the relation between I- and we-intentionality. Section 4 argues that I-intentionality and we-intentionality share a foundation of I-You intersubjectivity. Section 5 further develops the thesis that individuals, but also collectives, can be autonomous thinkers and agents in intersubjective contexts. The concluding section 6 situates the reasoning in a historical and contemporary context.

\section{Two senses of 'I': Sentience and sapience}

What role does the first-person singular 'I' play in discourse? To get anywhere, I will assume that a tokening of 'I' refers to whomever uttered it (quotation aside). For the sake of argument, it refers to the individual whose mouth or other air vibration-producing mechanisms cause it.

Why then is it improper to attribute an 'I' to, e.g., a radio producing the sound "I think..."? The answer I will propose is approached by considering that it is not unusual for a radio to

\footnotetext{
${ }^{1}$ I discuss how the argument of this paper relates to, among others, Schmid, in the concluding section.
} 
produce many incompatible "I think..." tokens; a first followed by another, "I disagree," and a third urging for reasons for the opposing views.

Perhaps it sometimes feels like that, when we deliberate about what to do, weighing reasons for and against alternatives. In the case of ourselves or another person it is, whereas for radios it is not, quite proper to attribute indecisiveness.

Part of an answer as to why is that we do not take radios to be autonomous points of view. They are not in the purview of our recognitive practices of attributing autonomous perspectives. A way to make sense of what that means is to think in terms of what we do in attributing intentionality. Two approaches to what we do will be reviewed. The second will later be employed in the argument that I-intentionality is socially constituted.

\subsection{Autonomous centers of adaptive activity}

On a first approach, attributing intentionality requires recognizing the other as a being with cognitive sophistication sufficient to cause behavior from an active first-person point of view; we recognize the other as a center of sensing and activity (De Jaegher \& Di Paolo, 2007, pp. 487-488).

If being B is capable reliably to autonomously respond differentially to, and interact in, an environment, then B is recognizable as an intentional individual. B must, first, be capable to differentiate stimuli, for instance as food or predators. Secondly, B must be an autonomous unified whole, not a part pulled about without agency of its own, like a doll in a dance (cf. De Jaegher \& Di Paolo, 2007, p. 495; Di Paolo, 2005, p. 443). For instance, a rabbit-tail moving around with the rest of the body disqualifies. Tails might reliably respond differentially to stimuli, but a tail does not have an autonomous point of view separate from the rest of the body. Third, B must be capable to adapt to environmental circumstances (Di Paolo, 2009, p. 14). To put it bluntly, a non-adaptive being is a soon-to-be-dead being. It (indeed, the species) does not survive long enough for recognition as an intentional individual.

Whether a being is intentional is, then, an issue of autonomous active sensing keyed to responsive dispositions to behaviorally differentiate, manage, manipulate and adapt. Let us call this the "Autonomous Center of Adaptive Activity" approach (ACAA-approach) to intentionality.

The ACAA approach is compatible with non-bio-chauvinist (possibly extended) causal functionalism. Otto and his notebook (Clark \& Chalmers, 1998) qualify as an intentional system, on ACAA. Enactive, autopoietic cognitive systems qualify too. Flagella bacteria, for instance, are autonomous and adaptive centers of activity, enacting a domain of significance in which, e.g., sucrose is nutritious (Thompson \& Stapleton, 2009). Nor is it ruled out that systems of socially interacting elements, as defined by Di Paolo and De Jaegher (2008; De Jaegher et al., 2010), realize autonomous centers of activity in the space of relational dynamics, dislocating the autonomy from interacting elements. 
Concisely put, for B to be recognizable as an intentional individual, on ACAA, B must,

(a) be reliably disposed to differentiate stimuli,

(b) act autonomously as a unified whole with a sensing point of view, and

(c) be able to adapt to environmental conditions.

I pointed out in the introduction that there are two senses of intentionality. One is the basic sense of having experiences; a sensing point of view. The other involves being able to think of or about thus-and-so that it is a certain way. From the point of view of that distinction, ACAA concerns the first sense. The following approach to what we do in attributing intentionality is concerned with the second sense.

\subsection{Social loci of responsibility}

The second approach emphasizes, as necessary for being an intentional individual, capacities to behave in ways entitling recognition as a participant in social practices of implicitly producing and consuming normative statuses (Brandom 1994; 2009, p. 28). Doing something 'implicitly' here means that one need not know that, or be able to say that, one does it in order nevertheless to do, and be taken to be capable to do, it.

Reasons are, on this view, what articulates intentional content, represented by the "...of X" which, together with an "I think...," constitutes an intentional nexus of a thinking 'I' and an ' $\mathrm{X}$ ' thought of.

According to Brandom, intentional states are commitments (beliefs are theoretical commitments, intentions are practical commitments). Their contents are determined by their position, or role, in inferential social practice. Reasons articulate that role. The practical significance of an action (or assertion) is conferred and articulable as the conjunction of reasons that entitle it and what the agent commits to as consequences of the act (or assertion). It is the role or point of intersection of the state in inferential practice that determines its content. Intentional content is what one is responsible for, given what one is already committed to and what one is committing to as a consequence of the present act (undertake consequential commitments to) (2006, p. 57).

For B to be an intentional 'I' requires, then, first that B is, and is capable to recognize others as, capable to give and ask for reasons (Sellars, 1956, §36). But since that capacity is practical know-how, B need not know that that is what it is doing (Brandom, 1994, chapter 1, section $3, \S \S 1-4)$. On this approach, intentions without content-articulating reasons are blind, as Kant, Wittgenstein, and McDowell might say. And being capable, at least implicitly, to give reasons if asked, is what an intentional individual is responsible to do. So B must, secondly, be recognizable as a locus of responsibility or else, at best, have mere blind, empty intentionality.

Individual intentionality is here a social achievement because normative (Brandom, 2000a). Recognizing and being recognized is reciprocal recognition as a "consumer and producer of reasons," which is to say normative statuses $(2009$, p. 128). The mutual recognition of each 
other as intentional is a social instituting of loci of responsibilities. No individual is an intentional 'I' prior to being taken to be one by those it takes to be ones; being taken into account, in the sense of being held responsible, and recognizing others as such units of accounts, is a constitutive feature of being an 'I.' This may suitably be called the "Socialized Loci of Responsibility” approach (SLR-approach) to intentionality.

The SLR-approach is, in contrast to ACAA, focused on sapience: a capacity implicitly to undertake and attribute responsibility, to identify and be identified as a unit of account whose commitments and entitlements can be tracked according to socially articulated inferential norms (Brandom, 1994). This is normative functionalism, in contrast to recent theories in philosophy of cognitive science more reminiscent of ACAA, such as the hypothesis of extended cognition, which are causal functionalisms. Thus while ACAA emphasizes causal agency, SLR emphasizes normative agency.

On SLR, then, attributing intentionality is attributing a socially articulated normative status. This does not mean that beings must be capable explicitly to think in terms of norms and reasons, or the inferences that articulate them, to be intentional individuals. But the capacity to do so is implicit in what they do, such that, in principle, they already know how to do everything they need to know how to do to be able, if they develop a language with sufficient expressive resources, to speak and think about themselves as responsive to reasons (Brandom, 2008, p. 115).

From the perspective of SLR, we can argue with Steiner (2014b) that causal-functional mechanisms, such as realized by brains, or non-neural things causally-functional on a par with brains, play a necessary causal role in producing behavior socially recognizable as implicit undertakings and attributions of responsibilities. But only indirectly. Causal-functional mechanisms are analogous to muscles: their proper functioning cause behavior to which normative statuses are attributable, but they do not themselves realize normative statuses.

Thinking of radios, pigeons, featherless bipeds and Martians, etc. (cf. Sellars, 1962), if you recognize them as capable implicitly to give and take responsibility, and if they reciprocate that recognition, you take each other to be intentional in the sense of being able to think of or about such-and-such that it is thus-and-so.

The sense of sociality and community involved in the SLR-approach deserves clarification. The co-existence of two or more individuals is not sufficient. Co-recognition is necessary; and a special kind of co-recognition. For individuals to constitute community, it is necessary that they recognize each other as capable, at least implicitly, to attribute and undertake commitments, hence to give and take responsibilities (Sellars 1962, pp. 76-77). Exercising capacities for mutual recognition of normative statuses is thus necessary for community - hence, a 'we' is a deontological way of being. In contrast, a mere group or collection, in the summative sense, does not require such recognition. And it is core to the SLR-approach that being an 'I,' as opposed to an autonomously sensing and behaving thing, is a deontological way of being.

To summarize, we have two approaches to in what sense organisms or things are intentional individuals. On ACAA, they are beings capable responsively to classify, sense, manage, adapt to and manipulate their being in the world. It is a form of sentient intelligence. On SLR, they are beings capable implicitly to recognize each other as producers and consumers of normative 
statuses. Capacities for the former may be necessary in order to develop capacities for the latter, but they are not sufficient.

In what follows I ask how we are to understand the relation between collective and individual intentionality on the SLR approach. The consequences of SLR for the issue of individual and collective intentionality turns out to be especially intriguing. It should be remembered, though, that SLR is not the only account of intentionality. I return to that point in the concluding section.

\section{From 'I-You' to 'I think...'}

In this section I argue that intentionality is socially constituted. The reasoning is HegelianBrandomian in spirit (Brandom 2002, chapters 6 and 7; 1999).

SLR says that intentional states are reciprocally recognized normative statuses. They are not properties of individuals but socially articulated proprieties; a matter of responsibilities undertaken and attributed (Brandom, 1994, pp. 47, 63; cf. Schmid, 2018, p. 242; Steiner, 2012, p. 288). An intentional individual is whatever is properly attributed responsibility, quite independently of privileged (e.g., causal-functional or neurological) properties.

On such premises, the argument that intentionality is socially constituted is not complicated. For, first, to take intentional states (e.g., beliefs, intentions) to be commitments (e.g., to assert, to act) is to take intentionality to be normative. Second, normative phenomena are social phenomena. This is a Hegelian point (an advance on Kant's de-ontologization of Descartes's ontological reification of mind as distinct substance). The point is that we cannot make sense of norms in abstraction from mutual recognitive, i.e., social, attitudes (cf. Brandom, 2007). For the sake of argument, assume the contrary, i.e., that it is sufficient for an 'I' to be committed to some act that it so takes itself. Then whatever the 'I' takes itself to be committed to is what it is committed to. Readers of Wittgenstein $(1953, \S 202)$ know well enough that this spells trouble. To paraphrase: if it is sufficient that I think that I am committed to $\mathrm{X}$ for me to be committed to $\mathrm{X}$, then my being committed collapses into my thinking that I am. If so, no distinction between being commitment and thinking that one is committed is to be had. SLR agrees on that point: it takes at least two points of view, involved in mutual recognition of each other as loci of responsibility, for either to be committed - hence, on SLR, to have intentionality.

Third, consider how the ' $\mathrm{X}$ ' in "I think of $\mathrm{X}$ " can be determinate. This is to ask how intentionality can have determinate content.

Representationalism provides a standard answer. According to it, subjects have capacities, typically sensory, to have subjective states that are of or about some X; a representational relation which, by being about some object, so to speak transcends the epistemological subjectobject divide. By way of that relation, an 'I' can fallibly "think of X."

In contrast to representationalism, SLR is a version of inferentialism. According to it, we need to talk about how dicta - which expresses what a thought is about by the use of 'that'-clauses - can be de re - of or about something, specified in 'of'-clauses (Brandom, 2000b, p. 359). It 
is here, in the gap between thinking that one thinks of $\mathrm{X}$, on the one hand, and thinking of X, whatever one thinks, on the other, that SLR turns to social relations to show how the ' $\mathrm{X}$ ' in "I hink of X" can be determinate.

What Brandom does to argue for it (e.g., 2000a, chapter 5; 1994, chapter 8) is simple enough despite its formal frame. To illustrate, suppose I think of X that it is copper. We can understand it in two ways.

One way is in a de dicto-frame: my thinking that $\mathrm{X}$ is copper. This is to focus on what I think that I think; what I acknowledge as a proper specification of the content of my thought. But we can also construe my thinking in a de re-frame: specifying what I am thinking of, that it is copper. This is a specification of what I am thinking of, even if $I$ do not acknowledge that that is what I think. What follows the 'that' in the first, de dicto-specification is what I think that I think, whatever I am in fact thinking of, which is specified in the de re-frame. This distinction allows us to say such things as "He is thinking of this silver coin that it is copper" and "The prosecutor is thinking of a habitual liar that he is a reliable witness." If the witness indeed is a habitual liar the prosecutor is thinking of a habitual liar that he is a reliable witness, independently of whether the prosecutor thinks that the reliable witness is a habitual liar. This is a way of specifying what the prosecutor is committed to, what he is responsible for, independently of his acknowledging it. Now, de re-specified contents of intentional states - i.e., that which the concerned individual might not acknowledge commitment to - are constitutive of the contents of all intentional states. Saying what an individual is thinking that she is thinking is to specify only one part of the content of an intentional state.

The social constitution or determination of (a part of) intentional content is seen more clearly in how the de re and de dicto specifications together drive a wedge between first- and secondperson perspectives. It creates a friction between social perspectives where what I am thinking of, on the one hand, and what I think that I am thinking, on the other, opens a space for social inferential practice in which my taking myself to be committed to $\mathrm{X}$ is different from my being committed to X. Thus, I may acknowledge commitment to something (the de dicto), thereby committing to consequences I do not acknowledge (the de re) (Brandom, 2004, p. 250). And the latter is part of the determination of my commitment (belief, intention, or other intentional state).

For instance, if I think of $\mathrm{X}$, that it is copper, I may from your point of view undertake commitment to $\mathrm{X}$ melting at $1083.4^{\circ} \mathrm{C}$. In that case it is improper for you to specify the content of my thinking as my thinking of $\mathrm{X}$ that it will melt at $1083.4^{\circ} \mathrm{C}$, because I am not thinking that. You are entitled to say, though, that I think of $\mathrm{X}$, which will melt at $1083.4^{\circ} \mathrm{C}$, that it is copper - and that I am, whether I know it or not, committed to it melting at $1083.4^{\circ}$.

In the example you (attempt to) articulate the content of my thought. This is how the inferentialism of SLR accounts for representation in terms of social inferential practice. What you do in the example - and what individuals do together in inferential practice in general - is using the entitlements we must already have mutually attributed to each other qua recognizing each other as cable to undertake commitments - to make each other's thoughts be representations determinately of some $\mathrm{X}$. 
I will have more to say about individual authority in rejecting others' specifications of one's own thinking in a later section. For now, we may note that, of course, anyone is entitled to object to anyone else's attribution of commitments. Thus, in the above example, I may object to your attributed commitment, saying "No, I don't think that it will melt at $1083.4^{\circ} \mathrm{C}$," entitling you, given your inferential commitments, to respond, "Then you are not thinking of copper." This is an illustration of a practice by way of which we (attempt to) determine the content of $m y$ thinking. Indeed, it is a practice necessary for what I think not to be whatever I think that I think it. What we do is to alternate between 'I-You'-perspectives in the context of which contents are made explicit and become determinately of something. Together we make out whether what some 'I' takes to be correct is correct. This social practice turns out to be interesting in relation to concerns about what the relation between ' $I$ '- and 'we'-intentionality is (cf. Crone, 2018, p. 271). Before investigating that consequence further, let me give a brief summary of the present section.

SLR is a normative and social inferentialism both about (a) intentionality, as a capacity, and, (b) the determinability of intentional contents. The former, (a), because having intentionality is a matter of being thus recognized by those one thus recognizes. The required recognition is as being capable to undertake and attribute normative statuses - commitments and responsibilities - accordingly as they stand in inferential relations. The latter, (b), because what anyone takes him- or herself that he or she is thinking of is not sufficient for it to in fact be what he or she $i s$ thinking of. The determinability of intentional contents requires cross-perspectivalness in social inferential practice; the mutual tracing of commitments. There may indeed be a causal relation such that if an $\mathrm{X}$ is present and I perceive it then I (will likely) come to believe that an $\mathrm{X}$ is present. But SLR says that for the correctness of my belief that an $\mathrm{X}$ is present to be determinate - i.e., to in fact be of $\mathrm{X}$ - requires more than the causal relation. What is required is that the belief be vetted in discursive practice. In that way we can become justified in saying that the representation is of $\mathrm{X}$ or rather of $\mathrm{Y}$ (e.g., I mistakenly believe of $\mathrm{Y}$ that it is X).

Consequently, on SLR, intentionality it is not a property of states or events (e.g., neurological) of individuals considered in abstraction from social and normative practice. Intentionality is thought of in terms of proprieties to attribute commitments, irrespective of private acknowledgments and, importantly, irrespective of (possibly extended) non-normatively specified neurological or other causal mechanisms. There is nothing 'in' individuals describable as the 'vehicles' of intentionality in a nonintentional, hence nonnormative, vocabulary (Steiner, 2014a). As Brandom puts it, approvingly commenting on Descombes (2001),

If we thought of our cognitive comportment in terms of commitments rather than beliefs, the model of inner states would not even be initially tempting. (Brandom, 2004, p. 251),

because a commitment, as normative status, is a social status and therefore not inner, in any traditional sense. Brandom is proposing that a normative, social inferentialism to intentional content is a way to cast off the vestiges of a Cartesianism which, in its modern form, construes intentional states as 'inner' (e.g., neurological), caused by something that is, on the same definition, outer.

What Brandom approves of in the above quote is what has recently been labeled vehicle-less intentionality (Steiner, 2014b, p. 456). According to it, to ask how the 'I' in "I think..." can 
transcend a subject-object gap so as to constitute an intentional relation to the ' $\mathrm{X}$ ' in " $\ldots$ of $\mathrm{X}$ " is wrongheaded. What is going on is rather a reciprocal social instituting of a second-person perspective which makes possible a relative independence between the autonomy of the 'I' to authoritatively commit itself, and thereby take responsibility for a position in inferential practices, on the one hand, and a 'You' holding the 'I' committed to produce entitlement to commitments undertaken, on the other. This is a game of "justifying and being able to justify" what one says or otherwise does (Sellars, 1956, §36) in which there are no vehicles of intentionality but a practice of articulating and thereby determining what is thought, said or otherwise done. Thus the Cartesian ego is saved from evils demons, not by subject-object transcending properties of representational relations but by social inferential practices.

The lesson is that determinate intentional content requires an I-You, which makes possible a relative independence between what I acknowledge to be committed and entitled to, on the one hand, and what responsibilities you and others are entitled to attribute and demand, on the other. Readers of Wittgenstein (1953) and McDowell (1996) can latch on to this story and say that only by encountering a 'You' in mutual normative recognition can the 'I' in "I think..." stand in determinate intentional relations to any ' $\mathrm{X}$ ' in the "... of $\mathrm{X}$."

The following sections leave the retrospective task of clarifying what others have had to say about senses of intentionality. I next look at what this story can teach us about the possibility of collective intentionality and its relation to individual intentionality.

\section{From I-You sociality to I-and-we-intentionality}

The aim now is to argue that whenever an 'I' is subject to proprieties instituted in I-You encounters a we-perspective is also constituted. This leads to a thesis about "the speculative identity of 'I' and 'we."”

On SLR, I-intentionality is possible only in mutual normative recognition of individuals as loci of responsibility. Whether an individual is an intentional subject is not, then, a matter of what kind of stuff it is (cf. Schmid, 2018). It is rather a matter of whether it can be taken to commit to stances in normative inferential practice; a practice which requires an I-You that opens for relative independence between individual authority (I think that ...) and socially articulated responsibility (You think of ... that...). An intersubjective setting "constituted by mutual (implicit) acknowledgement between conscious agents [an I-You]" (Crone, 2018, p. 273) is at the heart of any understanding of the concept of intentionality.

The speculative identity-thesis of 'I' and 'we' says that first-person singular and first-person plural intentionality are constituted by a type-identical intersubjective structure, namely, in social and normative inferential practice. An ' $\mathrm{I}$ ' is whatever singular point of view is capable to commit to stances in such practice; a 'we' is whatever plural point of view is capable to commit to stances in such practice. The latter, it will turn out, is a matter of co-occupation, not in the ontologically objectionable sense of co-occupation of one body or one mind, but in the de-ontological sense of one point, or set of points, of normative statuses (responsibilities) in social inferential practice. 
The argument for that thesis is implicit in the previous section. The I-You may be thought of as, as it were, a "social atom" (Gilbert, 2003). It is the minimum unit from which normative statuses can precipitate (Lo Presti 2015). That is, if it is not sufficient for me to have normative status $\mathrm{N}$ that I acknowledge that I have $\mathrm{N}$, but necessary that others also recognize $\mathrm{N}$ as properly attributable to me according to social inferential practice, then there must be several social perspectives of recognition in order for any one, in this case me, to have any N. Since being an ' $\mathrm{I}$ ' is an instance of having normative statuses, there is no ' $\mathrm{I}$ ' in abstraction from several social perspectives of mutual normative recognition. Although we may privately accept or reject norms, norms require sociality, where sociality is a deontological feature of the mutual, normative relations of recognition, not an ontological matter of, e.g., co-presence of organismic similarity. This is further spelled out by way of considering a problem in the reasoning in the previous section. Answering it helps show how 'I'- and 'we'-intentional subjects are both constituted, and simultaneously so, whenever an I-You is.

The problem implicit in the previous section is how there can be normative recognitive attitudes with which individuals mutually constitute an I-You and in which I-intentionality becomes possible. The obvious question is: Must not the recognitive attitudes be intentional, in order that they be of another as an 'I'? If so, the I-You presupposes I-intentionality, and the above reasoning is circular (cf. Martens \& Schlicht, 2018). Fortunately, there is a way out. The way out will bring a rationale for the speculative identity-thesis into view.

To move with calm, it is interesting to note that the later Wittgenstein, one and half a century after Hegel's Phenomenology of Spirit (1807), appealed to community (practices, institutions, forms of life) in answering how there can be determinately correct ways to continue a practice given a history of instances. Wittgenstein looked to communal practice at now, the instance of judging, as authoritative in deciding correctness. He found that any interpretation of practice as correct at an instant can be interpreted as correct or incorrect, hanging in the air along with what it interprets $(1953, \S 198)$. Hence he thought that, ultimately, the one 'I' must say "'This is simply what I do"' (\$217) and that whether what the one 'I' does is correct is a matter of communal practice.

Wittgenstein's regress-argument against private rule-following can be read as a response to Hegel's appeal to a point of view from tradition in judging the correctness of concept application. Wittgenstein is then read as saying that no point of view from tradition can determine correctness, for any interpretation of past correctness can itself be interpreted as correct or incorrect. But what Hegel is saying in the context of appeal to tradition, on the present reading (Brandom, 2002, chapters 6 and 7), is not that there is a determinate rule which stretches "like rails laid to infinity" (Wittgenstein, 1953, §218). Not at all. On Hegel's approach, instances of applying concepts (or judging what is correct) are moments in determining the concept (or what is correct). Concepts (rules) are dynamic for Hegel, and not, as they seem to have been for Kant, static determinates available for application. Rather, each application, for Hegel, contributes to continued and more specific determination of conceptual content, possibly by appeal to how concepts have been applied. Now, in application, we can be held and hold each other responsible by recognizing (or not) an authority in past applications. This is to see the history of a concept's application as implicitly authoritative (not totalitarian) in specifying its content (at now), without denying the authority of present users to hold each other responsible. 
If so, neither Wittgenstein's rule-following worries nor his answer by appeal to communal practice at now is an advance on Hegel. On the present reading, my taking past 'you's as authoritative and others as not, with respect to my applying a concept now, is a moment in the practice of determining content, according to Hegel. Hegel is not proposing a version of might be called "the conservative fallacy," on which something is correct now because it has been correct, like rails laid to infinity. Rather, he is expanding the mutual recognitive relation binding judges (concept-users) at now to incorporate also past ones (past 'you's). Thus he appeals to the authority and responsibility both of synchronous and diachronous perspectives as part of what constantly contributes to the further determination of always as-of-yet not fully determinate correctness (or conceptual content). And, of course, by transitivity of reasoning, the present also binds itself to the future (future 'you's) as judges over the correctness of present concept applications, just as the past bind itself to the present. So, present applications are to future ones what past ones are to the present; an implicit petition for mutual recognition in a diachronous practice of content-determination. Hence, it is not, as the Wittgensteinean worry suggests, a matter of the past determining future correctness, but a matter of present judgers (indeed, judgers at any present) petitioning for being recognized as authorities, by their present and future judgers, in determining correctness by making a decision, which can involve taking it to be correct (partly) according to tradition.

Before looking at how this helps solve the circularity-worry, I want to consider a reading of Hegel's identity-thesis of Self and Concept. The "Concept" is the whole of constitutive and re-constitutive moments in the determination of conceptual content (or correctness of practice) produced by a tradition; that is, how an 'I' now recognizes a past and present 'we' as authoritative for how to apply concepts (continue a practice) at the 'I's now, and a future 'we' as what the 'I' now petitions for recognition of, as an authority in that same practice.

Confusion results if we interpret the Self-Concept identity-thesis in what Brandom (1999, p. 176) calls a strict sense. According to the strict sense, Hegel is saying that 'I' and 'we' belong in the same ontological meta-conceptual category of objects, such that 'we' is a being ontologically on a par with an 'I' considered as organism - an additional material 'I' among others. This is implausible. No 'we' walks among us like other 'I's in that sense. And it is difficult to see what Hegel could take himself to commit to by saying so. Instead, Brandom suggest a speculative reading of the identity-thesis (pp. 176-177).

On the speculative reading, Self-Concept identity is a matter of mutual normative recognition. 'We' is, in the very same way as 'I,' constituted by such recognition. It is something an I-You, when constituted, constitutes. This does not entail that 'we' is an object in the same ontological meta-conceptual category as 'I's, existing as objects alongside them. What it means is that it is inevitable for the I-You of reciprocal normative recognition to constitute an 'I' and not constitute a 'we.' The structure of mutual normative recognition constitutive of the 'I' is the same structure as that constitutive of the 'we.' Therefore, whenever an 'I' is a 'we' is. This is an interpretation of saying that 'I' and 'we' are identical. The identity belongs in the realm of norms and proprieties, not, implausibly, in the realm of objects and their properties.

Returning to the circularity-worry, the worry was that the recognitive attitudes that institute an I-You must be intentional in order that they be recognition of another as an 'I.' If so, mutual recognition, as intentional, cannot account for I-intentionality, since it already involves it. The 
answer I have been approaching via the roundabout appeal to the speculative identity-thesis and the historicizing of determinateness, is that the I-You stands on the shoulders of predecessor collectives in addition to standing shoulder-to-shoulder in a present collective.

It is true that that answer does not allow us to say how I-intentionality came into being, as it were, at the dawn of sapience. (From a philosophical, rather than evolutionary point of view, the latter is not a main concern. ${ }^{2}$ ) What the present reasoning does is throw new light on the debate whether 'I' is more fundamental than 'we' (e.g., Zahavi, 2015a/b; 2018; 2019; contra Schmid, 2009; 2014a/b; 2018). We can now say that none is more fundamental than the other, because I-You encounters are fundamental to both. The 'I's in such encounters are not intentional in the SLR-sense prior to the intersubjective encounters in which (sentient) individuals first take each other to be 'I's. Moreover, their intentionality is determinable only in the context of such encounters. For instance, only if there is, minimally, an I-You of mutual normative recognition for an infant to be brought up into are conditions such that the infant can become an 'I' for itself and a 'we' together with others.

The I-You cannot be created ex nihilo without circularity, because there must be some, at least sentient, intentionality present for anyone to recognize anyone else. But insofar there are past 'you's, i.e., a history of recognition, no I-You need be created anew.

The way out of the circularity-worry, if it does not take us all the way out, is to loop it through history. So we find, in the instituting of an I-You of mutual normative recognition of commitments, entitlements, and responsibility, a social atom; the structural minimum capable of reciprocal normative recognition. It exhibits the minimum intentional structure which, when constituted, simultaneously constitutes an individual that can be 'me' or 'I' for itself, as well as to others, and a 'we' or 'us' together with others whom participate in the mutual normative recognition. In other words, there are 'I's only if there is a 'we,' and a 'we' only if there are 'I's, and both are possible only in the context of the I-You.

In an important sense, then, 'we' and 'I' are simultaneous constitueds revolving a shared constituent - the minimum I-You core of mutual normative recognition.

The next section argues that the present proposal helps reconcile the autonomy of individual intentionality with so-called intentional commonality. A common worry, going back at least to Mill (1872[1987), p. 65), via Popper (1945, p. 41), and recently to Searle (1995, p. 25), is that if community is as fundamental as individuality then individuals become normative "servants" or, metaphysically, a sub-category, to collectives. The worry is political totalitarianism and incredulous ontology, respectively. I will claim that while individual intentional autonomy is partly circumscribed, this is a necessary condition for any ' $\mathrm{I}$ ' to be autonomous to begin with.

\footnotetext{
${ }^{2}$ The present author take evolutionary theory to be correct (cf. Baker, 2005, pp. 26, 35-36).
} 


\section{I-autonomy and we-commonality}

An approach to intentionality as socially constituted should not lose sight of the fact that, most of the time, if not always, individual action is premised on individuals' own, autonomous, intentional states. This section aims to show that the present approach can account for individual autonomy. To do so, three theses, recently distinguished by Schmid, will be considered: Individual Intentional Autonomy (IIA), Intentional Commonality (IC), and Intentional Individualism (II). I will argue that while SLR suggests that individual intentionality requires sociality this does not threaten autonomy. The three theses are as follows:

IIA: “under normal circumstances, each individual's behavior has to be interpreted as his or her own action" (Schmid 2008, p. 25).

IC: it is possible to share "an intention in the straightforward sense of the word: one (token) intentional state, many participants" (p. 49).

II: "any interpretation of an individual's behavior has to be given in terms of individual intentional states" (p. 25).

My argument is, first, that IIA and II are possible only in an I-You context which, as argued in the previous section, is sufficient for we-intentionality. Hence, autonomy and individualism requires community. Second, IC, too, is possible only in the I-You context. The three - autonomy, commonality and autonomy - are thus argued to have the same conditions of possibility. In that sense, the argument here continues the pursuit of the 'I-we speculative identity thesis.' This, by the way, runs counter to Schmid, who argues that the 'we' may be more fundamental than the 'I' (more on which in the concluding section).

First, individuals achieve intentional autonomy only together in mutually recognizing each other as capable to give and take responsibilities in I-You encounters, on SLR. The notion of autonomy is not thereby abandoned, only sobered up, as follows.

Recall the relative autonomy-thesis and the distinction between de re and de dicto contentspecifications. A distinction between what I take to be correct, on the one hand, and what is correct across social perspectives, on the other, is required for I to think of something determinable, whatever I think that I think. It is my being held responsible, minimally by another, that expands my frictionless privacy into a social context necessary for 'I think [believe, desire, intend] of X that...' In this, I have authority to decide what to acknowledge, de dicto, that it is my thinking (say or judge what I think that I think it). But my exercising that authority does not determine what I am thereby committed to (what I think of). If it did, friction between my thin-king that I think of $\mathrm{X}$ and my thinking of $\mathrm{X}$ is lost. And frictionless intentionality is blind, empty.

Thus any 'I' can say, think and do whatever it likes, that it says, thinks or otherwise does it. That is its first-person authority. But what it does by saying, thinking, etc., it is not. Otherwise whatever it takes itself to have done is what it has done (Brandom, 2009, p. 145; Wittgenstein, $1953, \S 202)$. That throws it back into a situation of blind, empty intentionality. So individual intentional autonomy (IIA) becomes possible only if the 'I' partly subjects itself to social perspectives (giving up part of its first-person authority). The sobered up autonomy thesis is that I have authority to decide what to do that I do it, but not to what I am thereby committed, what 
I entitle others to hold me responsible for; what normative position I hold in social inferential practice.

For purposes of illustration, suppose that I (a) promise to drive you to the airport tomorrow morning, but that I (b) oversleep. I am not entitled to what I do in (b), because it violates (precludes entitlement to) the commitment in (a), whether or not I acknowledge it. I am free, barring duty and coercion, to (a); (a) is in my authority. But I have consequentially committed to not (b), and many other things I may never consider, again irrespective of whether I acknowledge it. So, that I commit is something I autonomously invest authority in. But what I thereby entitle others to hold me committed to and responsible for is not. This is a relative autonomy between force and content, where what I do that I do it is my authority but where what I have thereby done cannot be.

Hence individual autonomy is not totalitarian, suppressing all entitlements of others to hold one responsible. Autonomy is privileged authority, but conditional on recognition given and taken between the 'I' and at least one 'you' recognizing it as 'I.' Thus IIA is compatible with SLR, but the autonomy it involves is conditional on social and normative recognition.

The treatment of IIA implies that the individual intentional states in terms of which individual behavior has to be interpreted, according to II, are only partially the individual's intentional states. I-intentional content is determined in part across social perspectives in the I-You. While undertaken but possibly unacknowledged of-specifications of intentional contents are socially determined, acknowledged that-specifications are not. From the point of view of SLR, then, there is a clear sense in which every 'I' has "its own" intentional states that thus-and-so, in terms of which individual behavior has to be interpreted, in concordance with II. But that autonomy is possible only in a social context which, as it were, liberates the 'I' from having what it commits or entitles itself and others to to be whatever it takes it to be. A de dicto thatspecification of intentionality indeed specifies individual intentional states. But it is only a partial specification. The de re of-specification of intentionality specifies the other part, which involves others' interpretations of the individual in term of their beliefs, desires and other intentional states about what the interpreted individual acknowledges that it believes, desires or intends. That de re of-specification is not the individual's; it does not, as it is sometimes put, "belong to" the individual; it is not his or hers. Rather, it is up to those recognizing the individual as an 'I,' without whose recognition the individual cannot have determinate intentionality, to participate, preferably in discourse with the individual, in articulating what the individual is thinking of. Taking the latter away is throwing the individual back into a Cartesian situation in which he or she can only hope not to be betrayed by evil demons. Fighting them off can only be done together with others.

To summarize, SLR takes individuals to have autonomous authority to judge what de dictospecifications of their that-intentionality are correct. They authoritatively specify part of their intentional states. Individuals do not, though, have autonomous authority to judge what de respecifications of their of-intentionality are correct. These specify the other part of intentional states. The de re-specifications require social perspective-taking, and thus involves at least another individual's intentional states. So, from the point of view of SLR, IIA and II contain important insights: an interpretation of what an individual thinks, says, or otherwise does must 
be given in terms of intentional states part of which are his or her, with respect to which he or she is an authority.

We turn finally to IC. According to it, it is possible for several individuals to share a (token) intentional state. SLR has a straightforward way of making good on that possibility.

Recall that SLR is a kind of normative inferentialism. The content of a token intentional state is determined by its point of intersection among entitlements and commitments (what it is correctly inferable from) and what it entitles and commits to (what is correctly inferable from it). Let $\otimes$ symbolize such an inferential intersection. Suppose, then, that some individual $A$ acknowledge commitment that $p$ and some other individual B acknowledges commitment that $q$. Suppose further, that under the de dicto that-specification acknowledged by $\mathrm{A}$ and $\mathrm{B}, p \neq q$. Finally, let $p$ and $q$ both be correctly inferable from a set of commitment and entitlements $P$ and that a set of entitlements and commitments $Q$ is correctly inferable from both. In such a circumstance, A and B co-occupy an $\otimes$ in the de re- but not the de dicto-sense. SLR thus makes sense of IC; one token intentional state $\otimes$, many subjects. It is not about one mind or one body, but about co-occupation of normative position in inferential practice.

Of course A or B, or both, have the authority to refute that they co-occupy some intentional state (or, if they do not co-occupy one, to claim that they do). And insofar the that-specification of their commitments are concerned they have all the right and authority to do so. But if the issue is what their intentional states in fact are undertakings of, they are one token intentional state, irrespective of whether A and B acknowledge that.

Thus SLR, according to which intentional content consists in what it commits and entitles to according to socially articulated inferential norms, dovetails nicely with intentional commonality (IC). (It should go without saying that, on SLR, it is neither necessary nor sufficient for two individuals to share a token intentional state that they believe, intend or desire that they do so (cf. Schmid, 2009, p. 79)).

In conclusion, the social constitution of intentionality does not lose sight of autonomy and individuality. But SLR makes two qualifications. First, autonomy and authority is partial, not totalitarian; it stops at the dictum under which individuals acknowledge specifications of their commitments. It does not subdue de re-specifications. Second, the sense in which interpretations of an individual's behavior must be given in terms of the individual's intentional states, is narrowed; the part of the content of intentional states that is de re-specified, which is required to make an intentional state determinate, does not strictly speaking belong to the individual. It is socially cross-perspectival. Thus, the possessives "mine" or "the individual's" do not apply to the full content of an intentional state in terms of which an individual's behavior is interpreted. All the same, it is part of what makes it determinate. Therefore, others' intentionality partly determines the content of the individual intentional states in terms of which individual behavior is interpreted. With respect to IC, intentional states occupying the same space or inferential point of intersection in inferential practice are, insofar their contents are concerned, a shared token intentional state (indeed, not contents but one token content of several different individuals). 
The reasoning in this section aimed at showing that taking a social perspective on the nature of intentionality, as constituted in I-You normative intersubjectivity, contradicts none of the three theses discussed; individual autonomy, intentional individuality, and intentional commonality, respectively. Doing so has provided a second path to the speculative I-we identity thesis: several individuals have intentionality as one if their intentional states co-occupy an inferential point of intersection. (The first reason, given in the previous section, was that I- and we-intentionality share the normative I-You as a common structural minimum, such that whenever I-intentionality is realized we-intentionality is too, and vice versa.)

\section{Conclusions}

This concluding section first puts the pieces of the argumentation together in the historical context with which it started. Second, the argument is situated in context of a tendency, or movement, in recent contributions to the topic of collective intentionality, according to which it might fruitfully be approached from a social, normative, and inferentialist perspective.

The conclusion is that individual I- and shared we-intentionality are statuses inherent to social and normative practice. Neither I- nor we-intentionality, in the sense of SLR, can exist in abstraction from a social taking each other to be social loci of responsibility - perhaps the more basic ACAA-sense of intentionality can. When the social practice of mutual normative recognition is in place, conditions sufficient for both I- and we-intentionality are satisfied. Thus neither can fail to exist if the other does.

In a historical context, Kant's transcendental deduction of the 'I' is here replaced by a Hegelian social institution of the 'I,' which, qua institution, is on a par with 'we.' Despite his normative turn from Cartesian mind-substance to mind being an ability to follow and apply concepts as rules, Kant appears too caught up in the Cartesian tradition to see that the 'inner I' that was disappearing from Hume's inner eye need not be recaptured. It need not and cannot, because it was never in any sense inner to begin with. For applying and following concepts conceived as norms, to speak with Kant, is a status doings can have only in the social context of mutual normative recognition.

So thinking was never and could never be 'in here' as opposed to 'out there' (where?). The prepositional 'in,' in the context of 'in mind,' as a way of speaking about content, becomes, on the present account, an issue about what responsibilities a doing follows from and what responsibilities follow from it according to socially articulated inferential norms (an issue about deontological position; cf. Brandom, 2004; Steiner, 2014; de Prado Salas \& ZamoraBonilla, 2015; In press). This is a turn away from the issue where in the world mind is, as well as from the issue how it can reach beyond itself.

Descartes's ontological reification and Kant's transcendental idealism (and, indeed, Hume's introspective skepticism) are here seen to coincide at one core commitment: individualism (ontological, transcendental, and methodological, respectively). Consequently, they could not undertake, let alone acknowledge, entitlement to let the ' $I$ ' that thinks of something that it is thus-and-so be a socially instituted normative point of view. The dogma Kant could not shake off after Hume had awakened him from his dogmatic slumber is the dogma of individualism. 
Hegel, on the present interpretation, ${ }^{3}$ took issue with exactly that. Considering how to retain Kant's normative insight but turning his transcendentalism into a respectable philosophy of the self, his answer was an account of the self as a socially instituted normative position. A self can then be as much 'we' as 'I,' not as Cartesian we- or I-substance, not as Humean bundles of associated I- or we-ideas, nor as Kantian transcendental we- or I-selfs. Rather, it is because a self is a socially recognized point at which accountabilities intersect that there is no difference between an I and a we. So it makes sense to speak of 'my we' and 'our I' without losing sight of the many 'I's in a 'we,' or, indeed, of the many 'we's an 'I' partakes in, with their respective autonomy and authority.

Turning to contemporary developments in philosophy of social and cognitive science, the argument in this paper is part of a wider tendency. The point of departure I have taken is a commitment which many recent contributions co-occupy. Apart from those mentioned in previous sections (e.g., Brandom, Baker, and Schmid) de Prado Salas and Zamora Bonilla (2015; In press), and Steiner $(2012 ; 2014 \mathrm{a} / \mathrm{b})$ challenge the hegemony in analytic social philosophy and philosophy of mind that the 'I' is the primitive unit of intentionality. This movement, if it were one, is unhappy with recent debates on the nature of collective, shared or joint intentionality for still being in the clutches of methodological and ontological individualism.

This recent critical movement suggests that I-intentionality consists in relations (Schmid 2003) and that the interesting issue from a philosophical point of view is not where intentionality is or is caused ('in' whose mind? where 'in' brains?). The interesting philosophical issue is rather what we are doing in attributing intentionality. The budding answer is that we are not attributing - even indirectly - some brain state, or 'inner' mental state to something, but are rather tracking normative positions. Corporations and looser groups can have such positions insofar as they can be taken to commit to some act; to be responsible. Doing so is not to posit a realm of collective bodies or collective minds but to find that a normative position is cooccupied. In that way we-intentionality is no different from I-intentionality.

It then dawns that perhaps there is not a philosophical problem with collective intentionality which is not also a problem with individual intentionality; the debate what collective intentionality is supposed to be is just as much a debate about what individual intentionality is supposed to be. As Schmid has recently put it, "If you're worried about the plural ... and find it spooky, you should be worried about the individual ... and find it spooky, too" (2018, p. 241). Neither is more basic or more spooky than the other (contra Schmid 2005, e.g., pp. $138,148)$.

\footnotetext{
${ }^{3}$ Brandom is sometimes accused for reading his own commitments into classical philosophers. What such accusations fail to appreciate is that Brandom is not interested in de dicto, exegetical interpretation of what classical philosopher were committing to such that they would acknowledge those commitments if they were around today. He is rather giving us de re-interpretations of, e.g., Hume, Kant and Hegel; i.e., specifying what they are committing and entitling us to in our dialogue with them from the point of view of our present commitments and entitlements, whether or not they would acknowledge it (without thereby being ignorant of the authority they invested in their own words). So this interpretation cannot properly be accused on the grounds that "Hegel did not say that," but it may be accused on the grounds that "Hegel did not speak of this when saying that."
} 
I said that the argument of this paper share commitments with just mentioned trend in philosophy and (the philosophy of) social and cognitive sciences, admitting that the present contribution is not entirely novel. Nevertheless, ${ }^{4}$ and less modestly, the consequences those shared commitments entitle to, and which I have been elaborating here, are not pursued by Brandom, Baker, Steiner, or de Prado Salas and Zamora-Bonilla. Their concerns are with what an 'I' or 'person' is, as opposed to, but as constituted by, an organism, with conceptual content and intentionality, and with group deliberation and rationality. They do not bring the commitments their arguments in those contexts entitle us to endorse to bear on what we consequentially become entitled to say about the relation between I- and we-intentionality. Thus, they do not argue what I have argued - they do not speak of what I have been speaking of. It might be that what I have had to say reveals commitments implicit already in what they acknowledge that they are committed to. If so, I have made explicit an entitlement correctly inferable from shared commitments: that I-intentionality is not more fundamental than we-intentionality, nor vice versa. If not, this paper has, successfully or not, given a novel rationale for others with which it shares points of departure to draw the conclusion here drawn.

Schmid, by contrast, has contributed to the present debate. But he pays less attention to clarify how the details of a normative inferentialism, which it is far from clear that he would endorse, entitle anyone to say that 'we' is as fundamental as 'I.' Moreover, he claims that 'we' may be more fundamental than 'I' - a claim as much opposed here as the contrary claim that 'I' is more fundamental than 'we.' Furthermore, Schmid's concern is with plural and singular (prereflective) self-awareness, as approached from phenomenological and developmental perspectives. ${ }^{5}$ I have had as little to say on that topic as Schmid has had to say about such things as the speculative identity of 'I' and 'we,' the determinability of content and correctness in the context of a diachronous social perspective-taking between de dicto- and de re-specifications, and so on.

A consequence of all this - also glimpsed by Schmid, but for different reasons - is that something almost axiomatic in social science, and especially in economic theory, need be reconsidered: methodological individualism (e.g., Schumpeter, 1908, pp. 88-89; Weber, 1921[1988], p. 13; see Schmid, 2008). Methodological individualism is the stricture that, ultimately, only individual intentional states should be referred to in explanations of deliberation, decision and action. The rationale is that only individuals can think and act.

Now, if the argument of this paper is on the right track, that rationale for methodological individualism is shaky. For according to the present argument, an intentional 'individual,' in the sense of someone deliberating, believing, desiring, deciding and acting - which an individual relevant to economic theory presumably must be able to do - can be as much 'we' as 'I,' and, importantly, it cannot be an 'I' unless it also participates in some 'we.' For this reason, the present approach also dovetails with so-called realism about collectives. That is, a collective can indeed have a cognitive state such as belief (cf. List \& Pettit, 2011; Rupert, 2019). However, the present approach does not have that consequence as a matter of naturalistic principles

\footnotetext{
${ }^{4}$ I am grateful to an anonymous reviewer for urging me to clarify how this paper is not simply a repetition of previous contributions by, e.g., Brandom and Schmid.

${ }^{5}$ See especially his and Zahavi's exchanges on this topic (e.g., Schmid, 2014b; 2017; 2018; Zahavi, 2017; 2018; 2019; Brinck et al., 2017).
} 
about how individual and collective cognitive states are caused and realized (List, 2018; Rupert 2019, pp. 8-9). It is not because whatever causes of realizes our belief that $p$ is the same, if it can be, as whatever causes and realizes my belief that $p$ (e.g., a brain-state) that we can believe that $p$, but rather because they belong to the same social kind; they occupy the same point of intersection in a socially articulated space of normative inferential practice. That is not a fact about, e.g., brain-states or causal-functional equivalents (cf. Steiner, 2014b).

To end at the beginning, we may focus on ACAA-intentionality instead of SLR-intentionality. But if we do so we must not confuse the causal-functional capacities for sense-experience which we are then talking about with capacities for I- or we- 'thinking of $X$ that $p$,' which we talk about on the SLR-approach. While the former is almost obviously necessary for the latter it is equally obviously not sufficient. Mutual normative recognition is necessary for I- and wethinking but not for a cat to chase a dog or for a being with an autonomously sensing and acting point of view to experience pain and pleasure.

\section{Funding}

This research was funded by the Swedish Research Council, grant no. 2017-06361.

\section{Acknowledgements}

I want to thank the participants at the research seminars of the department of logic, history and philosophy of science at UNED, Madrid, Ingvar Johansson, and two anonymous reviewers at $A V A N T$ for comments and criticism that significantly helped improve on an earlier version of this paper.

\section{References}

Baker, L. (2005). When does a person begin? Social Philosophy and Policy, 22(2), 25-48.

Baker, L. (2015). Human persons as social entities. Journal of Social Ontology, 1(1), 77-87.

Baker, L. (2017). Naturalism and the idea of nature. Philosophy, 92, 333-349.

Brandom, R. (1994). Making it explicit. Cambridge, MA: Harvard University Press.

Brandom, R. (1999). Some pragmatist themes in Hegel's Idealism. European Journal of Philosophy, 7(2), 164-189.

Brandom, R. (2000a). Articulating reasons. Cambridge, MA: Harvard University Press.

Brandom, R. (2000b.) Facts, norms, and normative facts: a reply to Habermas. European Journal of Philosophy, 8(3), 356-374.

Brandom, R. (2002). Tales of the mighty dead. Cambridge, MA: Harvard University Press.

Brandom, R. (2004). From a critique of cognitive internalism to a conception of objective spirit. Inquiry, 47(3), 236-253. 
Brandom, R. (2007). The structure of desire and recognition: self-consciousness and self-constitution. Philosophy \& Social Criticism, 33(1), 127-150.

Brandom, R. (2008). Between saying and doing. New York, NY: Oxford University Press.

Brandom, R. (2009). Reason in philosophy. Cambridge, MA: Harvard University Press.

Brinck, I., Reddy, V., \& Zahavi, D. (2017). The primacy of the "we"? In C. Durt, T. Fuchs, \& C. Tewes (Eds.), Embodiment, enaction, and culture: Investigating the constitution of the social world (pp. 131-148). Cambridge, MA: The MIT Press.

Clark, A., \& Chalmers, D. (1998). The extended mind. Analysis, 58(1), 7-19.

Crone, K. (2018). Understanding others, reciprocity, and self-consciousness. Phenomenology and the Cognitive Sciences, 17, 267-278.

Crone, K., \& Huemer, W. (eds.) (2018). Investigating the social self. Phenomenology and the Cognitive Sciences, 17.

De Jaegher, H., \& Di Paolo, E. A. (2007). Participatory sense-making. Phenomenology and the Cognitive Sciences, 6, 485-507.

De Jaegher, H., \& Di Paolo, E. A. (2008). Making sense in participation. In F. Morganti, A. Carassa, \& G. Riva (Eds.), Enacting intersubjectivity: A cognitive and social Perspective to the study of interactions (pp. 33-47). Amsterdam: IOS Press.

De Jaegher, H., Di Paolo, E. A., and Gallagher, S. (2010). Can social interaction constitute social cognition? Trends in Cognitive Science, 14, 441-447.

de Prado Salas, J. G., \& Zamora Bonilla, J. (2015). Collective actors without collective minds. Philosophy of the Social Sciences, 45(1), 3-25.

de Prado Salas, J. G., \& Zamora Bonilla, J. (In press). Rational golems: collective agents as players of the reasoning game. In P. Stovall (Ed.), Inferentialism and collective intentionality. Springer.

Descombes, V. (2001). The mind's provisions: A critique of cognitivism. Translated by S. A. Schwartz. Princeton, NJ: Princeton University Press.

Di Paolo, E. A. (2005). Autopoiesis, adaptivity, teleology, agency. Phenomenology and the Cognitive Sciences, 4, 429-452.

Gilbert, M. (1989). On social facts. Princeton, NJ: Princeton University Press.

Gilbert, M. (2003). The structure of the social atom. In: F. F. Schmitt (Ed.), Socializing metaphysics (pp. 39-64). Lanham, MD: Rowman \& Littlefield.

Haugeland, J. (1982). Heidegger on being a person. Nous. 16, 16-26.

Hegel, G. W. F. (1807[1977]). Phenomenology of spirit. Translated by A. V. Miller. Oxford: Oxford University Press.

List, C. (2018). What is it like to be a group agent? Nous, 52(2), 259-319.

List, C., \& Pettit, P. (2011). Group agency. Oxford: Oxford University Press.

Lo Presti, P. (2015). Norms in social interaction: Semantic, epistemic and dynamic (doctoral dissertation). Lund: Lund University Publications. 
Martens, J, \& Schlicht, T. (2018). Individualism versus interactionism about social understanding. Phenomenology and the Cognitive Sciences, 17, 245-266.

McDowell, J. (1994). Mind and world. Cambridge, MA: Harvard University Press.

Mill, J. S. (1872[1987]). On the logic of the moral sciences. Peru, IL: Open Court.

Popper, K. (1945). The open society and its enemies. London: Routledge.

Rupert, R. (2019). Group minds and natural kinds. AVANT, 10(3), 1-28.

Schumpeter, A. J. (1908). Das Wesen und der Hauptinhalt der Theoretischen Nationalökonomie. Leipzig: Dunker \& Humblot.

Searle, J. (1990). Collective intentions and actions. In: P. Cohen, J. Morgan, \& E. Pollack (Eds.), Intentions in communication (pp. 401-416). Cambridge, MA: The MIT Press.

Searle, J. (1995). The construction of social reality. New York, NY: The Free Press.

Searle, J. (1998). Social ontology and the philosophy of society. Analyse und Kritik, 20, 143-158.

Sellars, W. (1956). Empiricism and the philosophy of mind. In: H. Feigl., \& M. Scriven (Eds.), Minnesota studies in the philosophy of science, vol. 1 (pp. 253-329). Minneapolis, MN: University of Minnesota Press.

Sellars, W. (1962). Philosophy and the scientific image of man. In: R. Colodny (Ed.), Frontiers of science and philosophy (pp. 35-78). Pittsburgh, PA: University of Pittsburgh Press.

Schmid, H B. (2003). Rationality-in-relations. American Journal of Economics and Sociology, 62(1), 67-101.

Schmid, H B. (2005). Wir-Intentionalität: Kritik des ontologischen Individualismum und Rekonstruktion der Gemeinschaft. Freigburg: Karl Alber.

Schmid, H B. (2008). Plural action. Philosophy of the Social Sciences, 38(1), 25-54.

Schmid, H B. (2009). Plural action: Essays in philosophy and social science. Dodrecht: Springer.

Schmid, H B. (2014a). Missing the 'we' for all those 'you's'. Grazer Philosophische Studien, 90, $35-62$.

Schmid, H B. (2014b). Plural self-awareness. Phenomenology and the Cognitive Sciences, 13, 324.

Schmid, H B. (2017). Collective responsibility and pre-reflective self-awareness. Philosophy \& Society, 28(4), 997-1034.

Schmid, H B. (2018). The subject of 'We intend'. Phenomenology and the Cognitive Sciences, 17, 231-243.

Steiner, P. (2012). Boundless thought. Manuscrito, 35(2), 269-309.

Steiner, P. (2014a). Enacting anti-representationalism. AVANT, 5(2), 43-86.

Steiner, P. (2014b). The delocalized mind. Phenomenology and the Cognitive Sciences, 13, $437-$ 460.

Thompson, E., \& Stapleton, M. (2009). Making sense of sense-making. Topoi, 28, 23-30. 
Tollefsen, D. P. (2002). Collective intentionality and the social sciences. Philosophy of the Social Sciences, 32(1), 25-50.

Tollefsen, D. P. (2006). From extended mind to collective mind. Cognitive Systems Research, 7, $140-150$.

Tuomela, R., \& Miller, K. (1988). We-intentions. Philosophical Studies, 53, 115-137.

Weber, M. (1921[1988]). Wirtschaft und Gesellschaft. Tübingen: J. C. B. Mohr.

Wittgenstein, L. (1953). Philosophical Investigations. Prentice Hall, NJ: Basil Blackwell.

Zahavi, D. (2015a). Self and other: from pure ego to co-constituted we. Continental Philosophical Review, 48, 146-160.

Zahavi, D. (2015b). You, me, and we: the sharing of emotional experiences. Journal of Consciousness Studies, 22(1-2), 84-101.

Zahavi, D. (2017). Pre-reflective self-awareness and experiential selfhood: singular and plural. Philosophy \& Society, 28(4), 1035-1060.

Zahavi, D. (2018). Collective intentionality and plural pre-reflective self-awareness. Journal of Social Philosophy, 49(1), 61-75.

Zahavi, D. (2019). Second-person engagement, self-alienation, and group-identification. Topoi, 38, 251-260.

Patrizio Lo Presti holds a postdoctoral position at the department of logic, history, and philosophy of science (UNED, Madrid) and at the department of philosophy at Lund University. His research focus is on philosophy of the social sciences, normativity, and philosophy of mind. Recent publications include: Lo Presti, P. (2020). Leave inference alone: Direct inferential social cognition. Theory \& Psychology, 30(2), 186-201; Lo Presti, P. (2020). Persons and affordances. Ecological Psychology, 32(1), 25-40; Lo Presti, P. (2019). Conceptual confusions and causal dynamics. Phenomenology and Mind, 17, 32-43.

The editorial and publishing process of this publication has been financed by the Ministry of Science and Higher Education from the funds for the dissemination of research (DUN) within the framework of publishing activity, contract no. 711/P-DUN/2019, period of implementation: the years 2019-2020. 